\title{
Deleted in malignant brain tumors 1 (DMBT1) elicits increased VEGF and decreased IL-6 production in type II lung epithelial cells
}

\author{
Hanna Müller ${ }^{1,2^{*}}$, Christian Nagel ${ }^{2}$, Christel Weiss ${ }^{3}$, Jan Mollenhauer ${ }^{4}$ and Johannes Poeschl ${ }^{2}$
}

\begin{abstract}
Background: Deleted in malignant brain tumors 1 (DMBT1) is an innate defence protein expressed in the lungs of preterm infants and adults. Recent studies showed that DMBT1 is important in angiogenesis and can bind to different growth factors including VEGF. We aimed at examining relationships between VEGF and IL-6 levels to DMBT1 expression in the lungs of preterm and term infants and in lung epithelial cells in vitro.

Methods: We examined by ELISA VEGF levels in 120 tracheal aspirates of 57 preterm and term infants and tested for correlation with different perinatal factors as well as with DMBT1 levels. To examine the effect of DMBT1 on VEGF and IL-6 expression we compared type II lung epithelial A549 cells stably transfected with a DMBT1 expression plasmid (DMBT1+ cells) to A549 cells stably transfected with an empty expression plasmid (DMBT1- cells). The concentrations of VEGF and IL- 6 were determined via ELISA in the supernatant of the unstimulated cells and after stimulation with LPS, TNFa and Phorbol-12-myristate-13-acetate (PMA).
\end{abstract}

Results: The VEGF levels in the tracheal aspirates of preterm and term infants were significantly correlated with DMBT1 levels $(p=0.0032)$, the postnatal age $(p=0.0073)$ and the presence of neonatal infection/sepsis $(p=0.0002)$. Unstimulated DMBT1+ A549 cells showed significantly higher VEGF expression $(p=0.0017)$ than DMBT1- cells. Significantly elevated VEGF levels were also confirmed for DMBT1+ cells after stimulation with TNFa $(p=0.0008)$, LPS $(p=0.0232)$ and PMA $(p=0.0025)$. The IL-6 levels were comparable in DMBT1+ versus DMBT1- cells without stimulation $(p=0.6028)$, but they were significantly reduced in DMBT1+ cells after stimulation with TNFa $(p=0.0003)$, LPS $(p=0.0088)$ and PMA $(p=0.0039)$.

Conclusions: The data indicate that DMBT1 promotes VEGF and suppresses IL-6 production in alveolar tissues, which could point to DMBT1 having a possible role in the transition from inflammation to regeneration and being a potentially useful clinical marker.

Keywords: DMBT1, VEGF, IL-6, Innate immunity, Lung epithelial cells

\section{Background}

DMBT1, a member of the scavenger receptor cysteinerich (SRCR) protein family, is known as a protein with functions in innate immunity, inflammation and epithelial cell differentiation [1-3]. Especially tissues with functions in maintaining a barrier to the environment as, for example, the lung or the gut show DMBT1 expression, which is up-

\footnotetext{
* Correspondence: Hanna.Mueller@uk-essen.de

'Department of Pediatrics I, Neonatology, University Hospital Essen,

University Duisburg-Essen, Hufelandstr. 55, 45147 Essen, Germany

${ }^{2}$ Division of Neonatology, Department of Pediatrics, University of Heidelberg,

Im Neuenheimer Feld 430, 69120 Heidelberg, Germany

Full list of author information is available at the end of the article
}

regulated upon inflammation [4-6]. Recently, DMBT1 has been reported to also exert functions in angiogenesis by influencing proliferation, migration and adhesion of endothelial cells. These functions could include binding of DMBT1 to different growth factors such as vascular endothelial growth factor (VEGF) and epidermal growth factor (EGF) [7].

The vascular endothelial growth factor (VEGF) represents a proangiogenic growth factor produced by cells such as pneumocytes, keratinocytes, macrophages, hepatocytes, and smooth muscle cells [8]. In various tissues, VEGF plays a role in normal and pathological angiogenesis, endothelial 
cell differentiation, maintenance and repair of existing vessels, embryonic development, microvascular permeability, and inflammatory processes.

VEGF is highly expressed in the lung and has multiple functions in the pulmonary tissue: It is necessary for lung development as well as for the structural maintenance during adult life [9-11]. Furthermore, VEGF affects the growth, proliferation and differentiation of type II pneumocytes $[12,13]$. Type II pneumocytes express the VEGF receptor VEGFR-2 [14], and VEGF up-regulates surfactant protein B and C [13]. Several studies described a role of VEGF in acute and chronic disease of the lung such as acute respiratory distress syndrome (ARDS), emphysema or pulmonary hypertension, pulmonary fibrosis, sarcoidosis, and after lung transplantation $[9,14,15]$. Beyond that, VEGF plays also a role in respiratory diseases of preterm infants, in the alveolarization of preterm lungs with respiratory distress syndrome characterized by edema and pulmonary inflammation, and in lungs with bronchopulmonary dysplasia $[8,13,16,17]$. Furthermore, VEGF is important for the pulmonary endothelial cells by functioning as a mitogen, survival and differentiation factor, promoting angiogenesis, and regulating the permeability of the endothelium [9].

Recent evidence that DMBT1 and VEGF are functionally linked in the regulation of endothelial cells and neoangiogenesis [7] prompted us to analyze as to whether similar relationships exist in the respiratory tract.

\section{Methods}

\section{Patients and tracheal aspirates}

To determine the VEGF concentrations we measured 120 tracheal aspirates from 57 included preterm and term infants (27 males, 30 females) treated at the Perinatal Center of the University of Heidelberg. These infants were part of the patients included in earlier studies of DMBT1 levels $[18,19]$. The newly determined VEGF levels were analyzed for correlation with DMBT1 levels from these earlier studies. The study was approved by the Ethics Committee of the University of Heidelberg, Germany, and the parents agreed by informed consent. The mean gestational age was $27.5 \pm 4.2$ weeks (postmenstrual age, range: 23-40 weeks), and the mean birth weight was $1128 \pm 839 \mathrm{~g}$ (range: $370-3610 \mathrm{~g}$ ).

The tracheal aspirates were obtained by applying 0.5 $1.0 \mathrm{ml} 0.9 \%$ sodium chloride solution into the endotracheal tubes and suctioning after three breaths of manual or mechanical ventilation. To adjust for different dilution factors associated with this procedure, we normalized the measured concentrations of VEGF or DMBT1 to the total protein content, which was detected with the bicinchoninic acid (BCA) protein assay (Pierce, Rockford, IL, USA).

Different factors were tested for correlation with VEGF levels in the tracheal aspirates, including parameters which vary within a patients' observational period (postnatal age in days and relative DMBT1 level in the tracheal aspirates, treatment with indomethacin and the occurrence of neonatal infection/sepsis or the need of surgery at distinct days of life; Table 1) as well as the following parameters, which remain constant for each patient: gestational age (postmenstrual age in weeks), birth weight, bronchopulmonary dysplasia (yes or no; defined as additional oxygen required at 36 weeks of corrected gestational age with abnormal radiological findings of the lung), asphyxia (yes or no), intraventricular hemorrhage (all grades), cerebral hemorrhage (intraventricular, cerebellar; yes or no), maximal grade of respiratory distress syndrome (RDS; no RDS or grade 1-4 according to Giedion et al. [20]), survival (yes or no), antenatal corticosteroids for lung development (complete, yes or no), maternal infection defined by increased C-reactive protein $(>5 \mathrm{mg} / \mathrm{l})$ often accompanied by maternal leukocytosis, fever and/or histological chorioamnionitis (yes or no), premature rupture of the membranes (yes or no, defined as more than 24 hours duration), small for gestational age (below the $10^{\text {th }}$ percentile; yes or no), number of days with infection/ sepsis (mean, range), and maximal grade of retinopathy of prematurity (RPM; no RPM, stage 1-5) (Table 2).

\section{Enzyme-linked immunosorbent assay (ELISA)}

We used an ELISA (Human VEGF Quantikine ELISA Kit DVE00, R\&D Systems GmbH, Wiesbaden-Nordenstadt, Germany) to determine the relative VEGF-A (here referred to as VEGF) levels in the tracheal aspirates. The assay is usable for tracheal aspirates in according to the recommendations of the company and the minimal detectable VEGF concentration is less than $5 \mathrm{pg} / \mathrm{ml}$. The VEGF levels were expressed in pg VEGF/ $\mu$ g total protein in order to adjust for differential dilution factors. The DMBT1 levels determined in two earlier studies were used for the comparison, where they were expressed as percentage of total protein content: $(\mu \mathrm{g}$ DMBT1/ $\mu \mathrm{g}$ total protein $) \times 100[18,19]$.

\section{Stimulation with TNFa, LPS and PMA}

Human lung epithelial A549 cells, which were used in this study, have the characteristic morphology of type II lung epithelial cells, show typical lamellar bodies and form confluent monolayers [21]. The cells were stably

Table 1 Correlation of non-constant parameters with the VEGF concentration in 120 tracheal aspirates of 57 infants

\begin{tabular}{ll}
\hline Parameter & $\mathbf{p}$-value \\
\hline Postnatal age (days) & $\mathbf{0 . 0 0 7 3}$ \\
DMBT1 concentration in tracheal aspirates & $\mathbf{0 . 0 0 3 2}$ \\
Infection/sepsis & $\mathbf{0 . 0 0 0 2}$ \\
Treatment with indomethacin & 0.1669 \\
Surgery & 0.8733 \\
\hline
\end{tabular}


Table 2 Correlation of constant parameters with the VEGF concentration in tracheal aspirates of $\mathbf{5 7}$ infants

\begin{tabular}{|c|c|c|}
\hline Parameter & & p-value \\
\hline $\begin{array}{l}\text { Gestational age (postmenstrual age in weeks, } \\
\text { mean } \pm \text { standard deviation) }\end{array}$ & $27.5 \pm 4.2$ & 0.9230 \\
\hline Birth weight ( $g$, mean \pm standard deviation) & $1128 \pm 839$ & 0.6718 \\
\hline Bronchopulmonary dysplasia (n) & $34(60 \%)$ & 0.3076 \\
\hline Asphyxia (n) & $7(12 \%)$ & 0.4642 \\
\hline Intraventricular hemorrhage (all grades) & $16(28 \%)$ & 0.2607 \\
\hline $\begin{array}{l}\text { Cerebral hemorrhage } \\
\text { (intraventricular, cerebellar, n) }\end{array}$ & $17(30 \%)$ & 0.2782 \\
\hline Respiratory distress syndrome (n) & $50(88 \%)$ & 0.7636 \\
\hline $\begin{array}{l}\text { Maximal grade of respiratory } \\
\text { distress syndrome (RDS) }\end{array}$ & & 0.4284 \\
\hline No RDS (n) & $7(12 \%)$ & \\
\hline Grade 1 (n) & $6(11 \%)$ & \\
\hline Grade 2 (n) & $18(32 \%)$ & \\
\hline Grade 3 (n) & $20(35 \%)$ & \\
\hline Grade 4 (n) & $6(11 \%)$ & \\
\hline Survival (n) & $49(86 \%)$ & 0.8802 \\
\hline $\begin{array}{l}\text { Antenatal corticosteroids for lung } \\
\text { development (complete, } n \text { ) }\end{array}$ & $32(56 \%)$ & 0.9443 \\
\hline Maternal infection (n) & $23(40 \%)$ & 0.4403 \\
\hline Premature rupture of the membranes (n) & $8(14 \%)$ & 0.2180 \\
\hline Small for gestational age (n) & $15(26 \%)$ & 0.4428 \\
\hline $\begin{array}{l}\text { Number of days with infection } \\
\text { (median, range) }\end{array}$ & $11(0-80)$ & 0.7470 \\
\hline Retinopathy of prematurity (n) & $34(60 \%)$ & 0.9268 \\
\hline $\begin{array}{l}\text { Maximal grade of Retinopathy of } \\
\text { prematurity (RPM) }\end{array}$ & & 0.6947 \\
\hline No RPM & $23(40 \%)$ & \\
\hline Stage 1 (n) & $4(7 \%)$ & \\
\hline Stage 2 (n) & $16(28 \%)$ & \\
\hline Stage $3(n)$ & $14(25 \%)$ & \\
\hline Stage $4(n)$ & 0 & \\
\hline Stage $5(n)$ & 0 & \\
\hline
\end{tabular}

transfected with an expression plasmid coding for the largest $(8 \mathrm{~kb})$ DMBT1 variant (DMBT1+ cells) under the control of a constitutive promoter or with an empty expression vector (DMBT1- cells) as described previously [22].

A549 cells were cultured with DMEM medium without phenol red (PAN-Biotech, Aidenbach, Germany) containing $10 \%$ fetal bovine serum, $1 \%$ L-glutamine and penicillin/streptomycin. Hygromycin B, used for the selection of cells with insertion of the plasmids, was added at a final concentration of $500 \mu \mathrm{g} / \mathrm{ml}$ to keep the cells under selection pressure. Cultivation was performed at $37^{\circ} \mathrm{C}$ and $5 \% \mathrm{CO} 2$.

In experiments without stimulation $7.5 \times 10^{5}$ cells were cultured with medium containing fetal bovine serum (FBS) until $90 \%$ confluence in a well of a 6-well plate was reached. The medium was removed and replaced with FBS-free medium for 48 hours. The supernatants of the confluent cell culture were then carefully removed, centrifuged at $1,500 \mathrm{rpm}$ to remove remaining cells, and then frozen at $-20^{\circ} \mathrm{C}$ until determination of the VEGF and IL- 6 concentrations. The confluent cells on the cell culture plates were removed with trypsin from the wells and counted with a Neubauer chamber. Trypan blue staining was used to count the viable cells, enabling a calculation of the VEGF and IL-6 concentration referred to the number of viable cells.

In the case of stimulation the cells were incubated in FBS-free medium with LPS ( $10 \mu \mathrm{g} / \mathrm{ml}$ for 48 hours), TNF $\alpha$ (10 $\mathrm{ng} / \mathrm{ml}$ for 48 hours) and Phorbol-12-myristate-13acetate (PMA; $50 \mathrm{ng} / \mathrm{ml}$ for 48 hours). After stimulation the supernatant was harvested and analyzed for VEGF and IL-6 as described above.

\section{Determination of VEGF and IL- 6 concentrations in supernatants of $A 549$ cells by ELISA}

The expression of VEGF-A and IL- 6 in the supernatants of A549 cells was measured with an ELISA for human VEGF and for human IL-6 (Human VEGF Quantikine ELISA Kit DVE00 and Human IL-6 Quantikine ELISA Kit D6050, R\&D Systems GmbH, Wiesbaden-Nordenstadt, Germany). The assays are both usable for cell culture supernatants in according to the recommendations of the company. The minimal detectable VEGF concentration is less than $5 \mathrm{pg} / \mathrm{ml}$ and the minimal detectable IL- 6 concentration is less than $0.70 \mathrm{pg} / \mathrm{ml}$. The VEGF and IL- 6 concentrations were then calculated in $\mathrm{pg} / \mathrm{ml} / 100,000$ viable cells.

\section{Western blot}

Western blot analysis was performed to confirm DMBT1 expression in DMBT + versus DMBT1- cells by using a polyacrylamide gel and non-reducing conditions. The polyclonal antibody anti-DMBT1p84 was used to detect DMBT1 as described previously [7]. An antibody against heavy chain non-muscle myosin (NMMHC, DPC Biermann, Bad Nauheim, Germany), a structure protein like $\beta$-actin, was employed as reference protein to allow comparison of the different samples. After incubation with the secondary antibody anti-rabbit-IgG conjugated to horseradish peroxidase the analyzed proteins were detected and visualized by ECL Western Blotting Substrate.

\section{Statistics}

All statistical calculations have been done with SAS software, release 9.3 (SAS Institute Inc., Cary, NC, USA). For categorical parameters, absolute and relative frequencies are given. Quantitative parameters are presented as mean value and standard error of mean (SEM) together with minimum and maximum. In the case of outliers the median value has been calculated. In order to estimate correlations 
between quantitative parameters (i.e. postnatal age, DMBT1 concentrations, gestational age, birth weight) and the outcome variable "VEGF level", regression analyses have been used. Variance analyses have been performed for testing the influence of qualitative parameters on the outcome variable. To create a formula calculating the VEGF content of an unknown tracheal aspirate we performed a multiple regression analysis. All these analyses have been performed with the SAS procedure PROC MIXED where patients' ID was considered as a random variable and the parameters being tested as fixed variables. Furthermore, we compared DMBT1+ versus DMBT1- cells regarding VEGF and IL6levels using the 2 sample t-tests or Mann-Whitney U-tests as appropriate. Test results with p-values smaller than 0.05 were regarded as statistically significant. In cases of multiple comparisons we performed a correction for multiple testing.

\section{Results}

\section{VEGF concentrations in tracheal aspirates}

The mean VEGF-A (hereafter referred to as VEGF) concentration in the tracheal aspirates of the 57 preterm and term infants was $0.7524 \pm 0.8882 \mathrm{pg} / \mu \mathrm{g}$ total protein with a range of 0.008 to $4.609 \mathrm{pg} / \mu \mathrm{g}$ total protein. The relative VEGF levels were significantly associated with the postnatal age, the earlier determined DMBT1 levels $[18,19]$ in the tracheal aspirates and with neonatal infection/sepsis (Table 1, Figure 1). The other parameters, including gestational age, birth weight, bronchopulmonary dysplasia, respiratory distress syndrome and retinopathy of prematurity, showed no association with the relative VEGF levels of the tracheal aspirates (Table 2).

Furthermore, we performed a multiple regression analysis including these factors, which have been revealed as statistically significant, in the univariate analyses. This led to the following mathematical equation:

$$
y=0.2840+0.007356 x_{1}+0.1569 x_{2}+x_{3}
$$

where $Y$ is the relative VEGF level (pg VEGF/ $\mu$ g total protein) in the unknown tracheal aspirate, which is significantly influenced by the parameters postnatal age (in days, $X_{1}, \mathrm{p}=0.0427$ ), the relative DMBT1 level expressed as percentage of the total protein concentration $(\mu \mathrm{g} \mathrm{DMBT} 1 / \mu \mathrm{g}$ total protein $\times 100)$ in the tracheal aspirate $\left(X_{2}, \mathrm{p}=0.0159\right)$ and the presence or absence of neonatal infection/sepsis $\left(x_{3}=0.4891\right.$, if the infant has an infection/sepsis or $x_{3}=0$ in the absence of infection/ sepsis; $\mathrm{p}=0.0038$ ).

In conclusion, correlation of VEGF levels with postnatal age, infection/sepsis and DMBT1 levels is in good agreement with the findings that DMBT1 levels also correlated with postnatal age and infection/sepsis according to an earlier study [18].

\section{DMBT1 promotes basal and inducible VEGF expression in A549 cells}

Because the VEGF and the DMBT1 levels in the tracheal aspirates were significantly correlated, we next tested as to whether this might be based on a causal relationship. We therefore employed A549 lung epithelial cells with and without DMBT1 expression. DMBT1-positive A549 cells (referred to as DMBT1+ cells) were constructed using the expression plasmids described before [22] Control cells were constructed in parallel using an empty expression plasmid. Western blot analyses confirmed expression in DMBT1+ cells, while no detectable protein levels were observed for A549 cells carrying the empty expression plasmid (Figure 2), so that we will refer to the latter as DMBT1- cells.

We next determined the basal VEGF levels in the two cell lines as well as the VEGF levels after stimulation with TNF $\alpha$, LPS, or PMA. DMBT1+ cells displayed significantly elevated VEGF levels in the basal state as well as after stimulation, regardless of whether TNF $\alpha$, LPS, or PMA was used (Figure 3). This clearly indicated that the presence of DMBT1 primes the lung epithelial cells for an enhanced VEGF production and confirms a causal relationship.

\section{DMBT1 suppresses IL-6 production in A549 cells}

IL-6 is a well-known pro-inflammatory mediator in respiratory tract tissues, and, among various other effects, elicits increased VEGF production [23]. On the other hand, studies of intestinal inflammation in $\mathrm{Dmbt} 1^{-/-}$ mice revealed that, in this tissue, DMBT1 may function in suppression of inflammation and IL-6 production via a role as pattern recognition molecule $[5,6,24]$. We thus evaluated next the IL-6 levels in alveolar epithelial A549 cells with and without DMBT1 expression. In the absence of inflammatory stimuli, DMBT1 did not elicit significant changes in IL-6 levels. By contrast, compared to DMBT1- cells, the DMBT1 expressing A549 cells displayed significant suppression of IL-6 production after stimulation with any of the three pro-inflammatory stimuli (TNF $\alpha$, LPS, and PMA; Figure 4). This remarkably suggested that DMBT1 may substitute the IL-6 function in up-regulation of VEGF.

\section{Discussion}

Proper spatio-temporal regulation of VEGF production is of critical importance for the respiratory tract. A distinct VEGF gradient is required for development of the airway tubular structures and lung endothelium, while VEGF overexpression may lead to dysmorphogenesis of the lung [9]. In pulmonary diseases like ARDS VEGF can aggravate the disease in a concentration-dependent manner by induction of endothelial permeability or can support the healing process. Different mechanisms are 

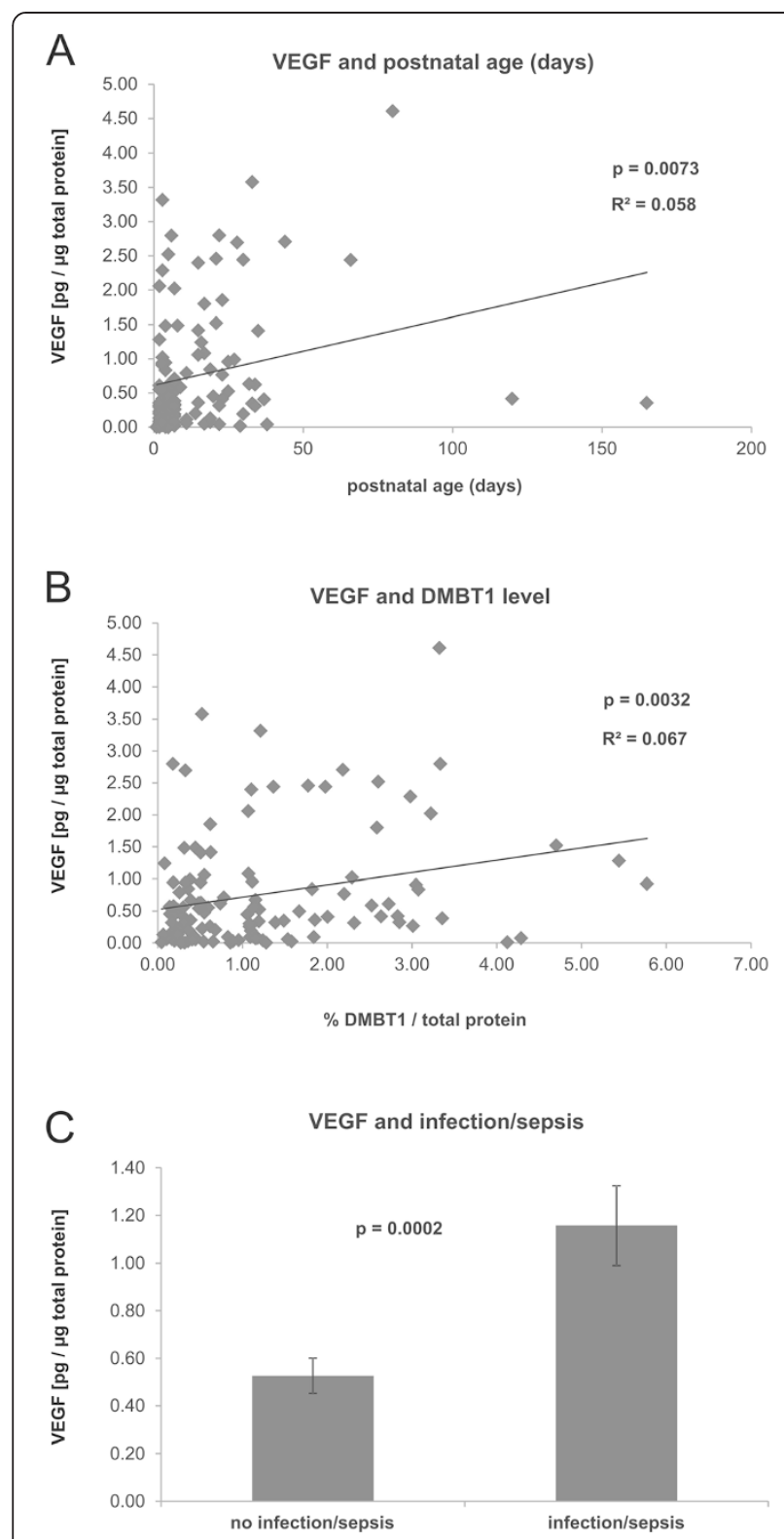

Figure 1 Significant correlations between VEGF levels and tested parameters. Correlations were established by testing of tracheal aspirates ( $n=120)$ from infants and tested for significance via regression analysis or ANOVA using the SAS procedure PROC MIXED. (A) VEGF levels were significantly correlated with the postnatal age of the infants $(p=0.0073)$. (B) Positive correlation of VEGF levels with relative DMBT1 levels in the tracheal aspirates $(p=0.0032)$. (C) Significantly increased VEGF levels (mean \pm SEM) in aspirates from infants with versus without infection/sepsis $(p=0.0002)$.

discussed to regulate intrapulmonary VEGF levels. Firstly, the loss of pneumocytes type II leads to decreased VEGF production. Secondly, proteases from inflammatory cells can degrade VEGF. Thirdly, more pulmonary VEGF can leave the lung across the alveolar-capillary barrier upon increased permeability. At fourth, soluble VEGFR-1, a splice variant of the membrane bound VEGFR-1, is a

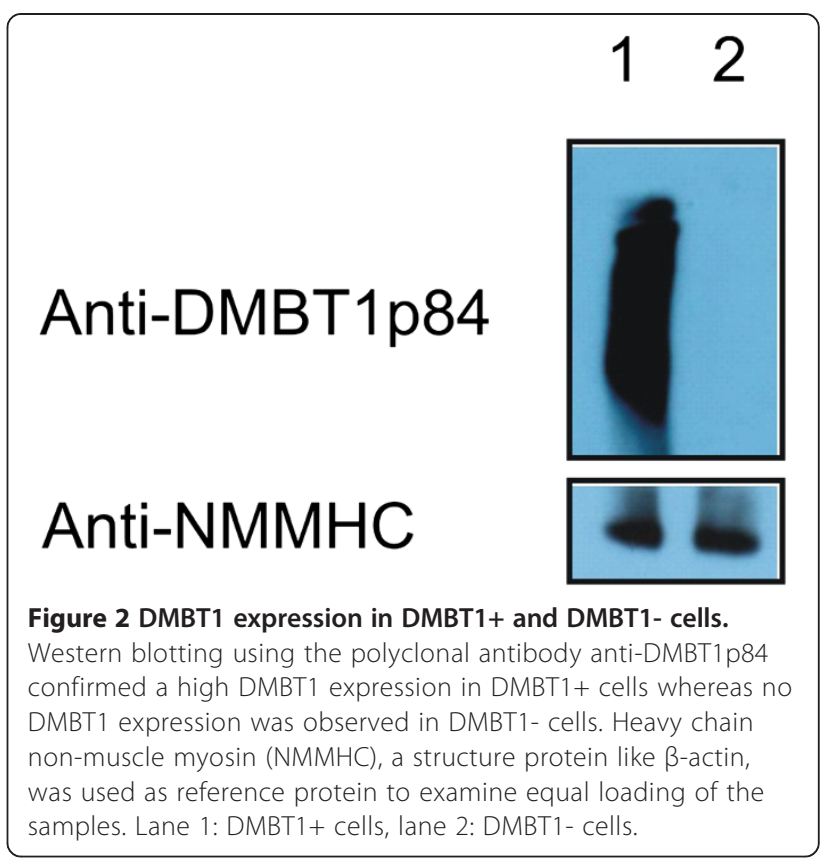

potent antagonist of the bioactive VEGF and influences the bioactivity of the VEGF present in the lung. Finally, other inhibitors of VEGF bioactivity in the lung contribute to its regulation such as ADAMTS1 and connective tissue growth factor $[15,25]$. Because understanding VEGF regulation is thus critical for understanding the basis of respiratory disease, we here addressed possible links between the secreted factor DMBT1 and VEGF.

\section{Influence of perinatal factors on VEGF levels in the tracheal aspirates of preterm and term infants}

Our study revealed a correlation between the VEGF levels and postnatal age, but not with the gestational age or birth weight. This is in agreement with the study of Lassus et al., who examined 189 tracheal aspirates of 44 preterm infants in the first postnatal week and described an increase of VEGF concentration and no correlation with gestational age or birth weight [26]. However, in contrast to our study higher VEGF concentrations in infants of mothers with chorioamnionitis or premature rupture of the membranes and lower VEGF concentrations in infants with BPD or maternal preeclampsia were reported. Additionally, a negative correlation between VEGF levels and the number of surfactant doses was demonstrated in this study [26]. Another studies reported reduced VEGF levels in bronchopulmonary dysplasia of preterm infants, which is a neonatal chronic lung disease with reduced number of alveoles and reduced microvascular density $[17,27]$. Moreover, other authors reported that VEGF levels in tracheal aspirates of mechanically ventilated preterm neonates are not associated with BPD. Also in this study no correlation between birth weight and VEGF levels or 


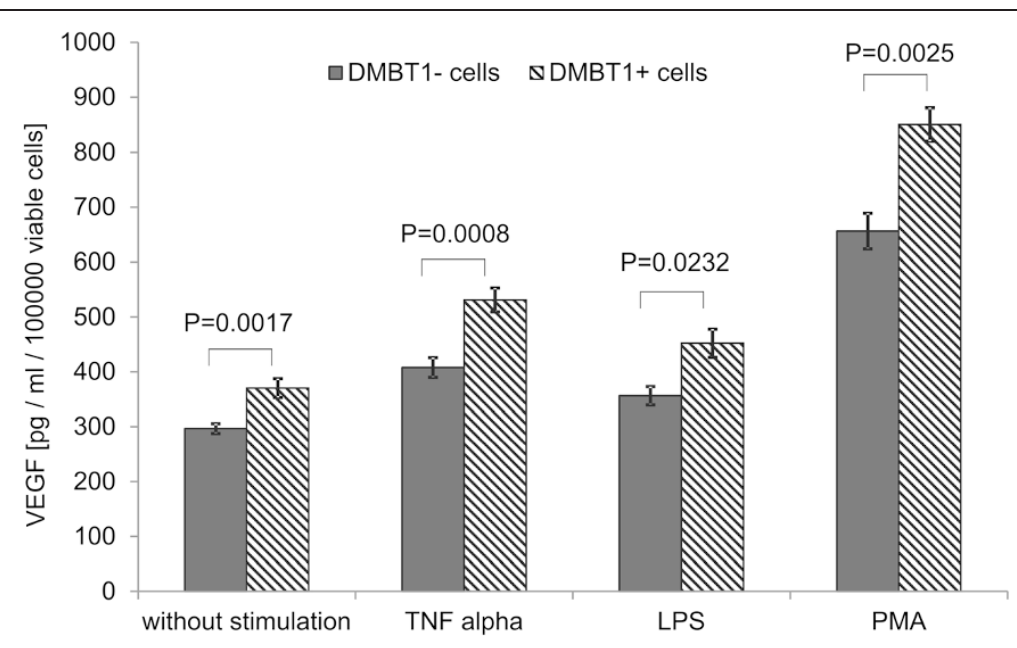

Figure 3 VEGF levels in unstimulated and stimulated DMBT1+ and DMBT1- cells. VEGF levels were determined in cell culture supernatants by ELISA. DMBT1+ cells showed significantly elevated VEGF levels in the basal state without stimulation as well as after stimulation with TNFa, LPS, or PMA. The VEGF mean values of the cell culture wells are shown for different stimulations and separately for DMBT1+ and DMBT1- cells. Error bars represent standard error of the mean. Sample sizes of the eight resulting subgroups were between 5 and 14. The $p$ values were derived from 2 sample t-tests which have been used to compare the VEGF mean values for DMBT1+ and DMBT1- cells.

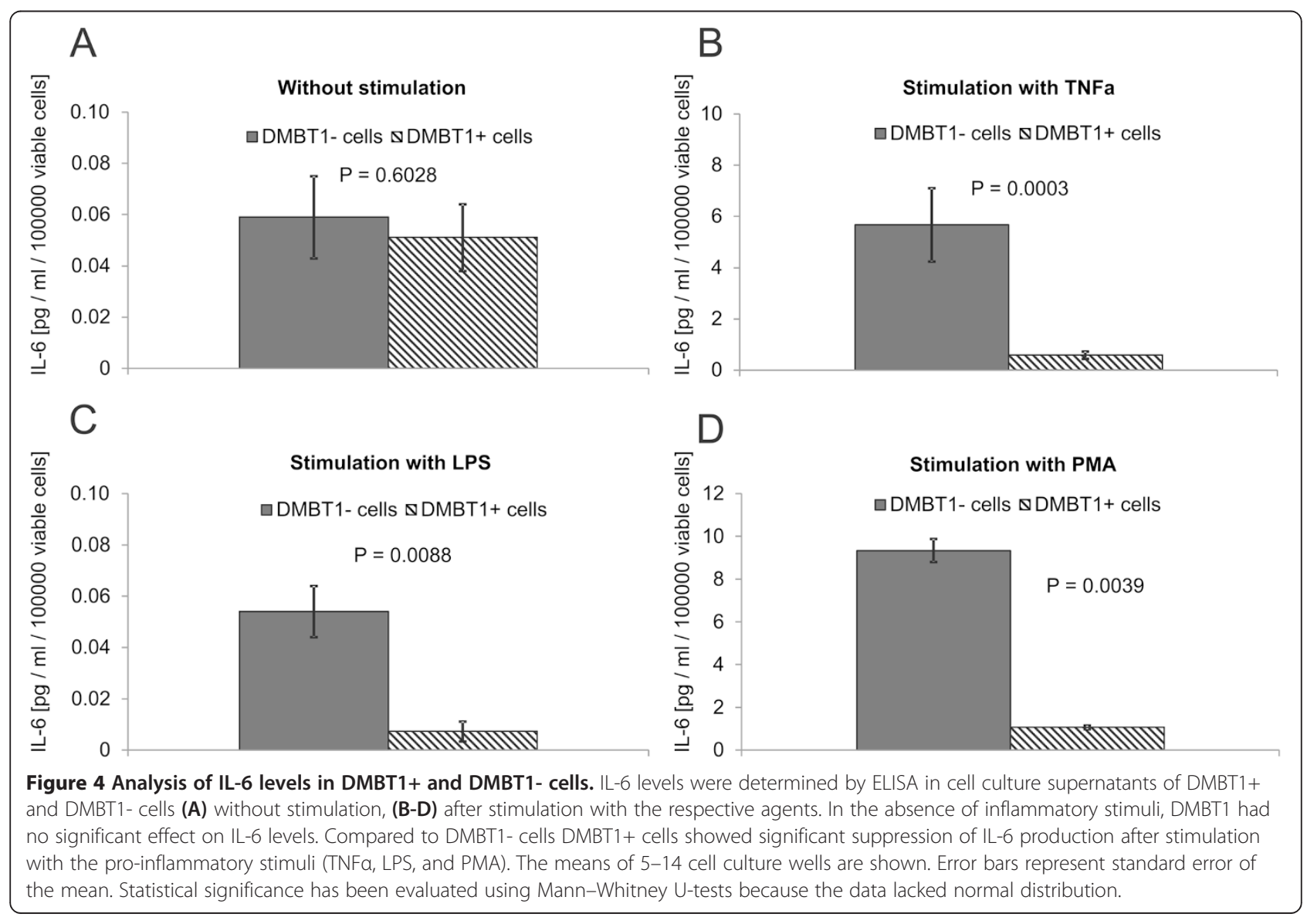


gestational age and VEGF levels in tracheal aspirates could be detected [28]. In summary, our data confirm an increase of VEGF levels with postnatal age as reported by other authors [26].

\section{Correlation between pulmonary DMBT1 and VEGF levels in tracheal aspirates of preterm and term infants}

The VEGF concentrations determined in this study for the tracheal aspirates of preterm and term infants showed a significant correlation with the DMBT1 levels determined earlier [18,19]. Confirmed causal relation was established by the significantly higher VEGF concentrations in the supernatants of the DMBT1+ cells in comparison to the DMBT1- cells. Thus, DMBT1 not only may interact with VEGF [7], but obviously is also a positive regulator of VEGF in type II lung cells.

\section{VEGF regulation in the respiratory tract}

Inflammation and angiogenesis are intimately linked to each other. VEGF may affect immune surveillance and modulation [9]. IL-6 and TNF $\alpha$, both involved in increased vascular permeability and remodeling, are able to induce VEGF expression and IL-6 as well as VEGF are up-regulated in response to hypoxia [25]. In early stages of acute lung injury the pro-inflammatory cytokines induce the expression and release of VEGF from pneumocytes type II, alveolar macrophages and neutrophils [25]. The observation that A549 cells constitutively produced VEGF was confirmed by different studies [29-31]. Clinical studies showed that LPS-induced lung injury is characterized by an increased pulmonary VEGF expression [25]. Prostacyclin-induced VEGF production is cyclooxygenase-2-dependent and PMA induced the expression of COX-2 [32,33]. PMA is an activator of the protein kinase $\mathrm{C}$. The induction of VEGF by PMA via protein kinase $\mathrm{C}$ activation is also known from human endothelial cells [34]. Luo et al. reported about a nonsignificant increase of VEGF after stimulation of A549 cells with PMA $(0.1 \mu \mathrm{M}$ for 12 hours), but the stimulation with both, PMA and COX-2, led to a significant increase of VEGF expression [35]. In our study, we observed an increase of VEGF expression, when stimulating A549 cells with $50 \mathrm{ng} / \mathrm{ml}$ PMA for 48 hours. Other studies showed that inhibition of the protein kinase $C$ led to significantly decreased VEGF secretion in primary human airway epithelial cells [36]. We observed that DMBT1 significantly elevated VEGF levels in type II lung cells in the basal state as well as after stimulation with pro-inflammatory agents. Within the light of the recently established role of DMBT1 in angiogenesis [7] it is thus conceivable that DMBT1, besides active participation in innate immunity, participates in the initiation of regeneration and/or in the transition from inflammation to regeneration in the respiratory tract.

\section{DMBT1-mediated IL-6 suppression}

Pro-inflammatory stimuli induce a stimulation of NF- $\kappa B$ followed by induced transcription of pro-inflammatory mediators such as IL-6, COX-2 and TNFa. The proinflammatory cytokines IL- 6 and TNF $\alpha$ are secreted to the tracheal aspirate fluid of infants with meconium aspiration syndrome [37]. Pulmonary IL-6 is increased in preterm infants developing BPD and in BPD lungs [38]. Further, the tracheal aspirate cells from preterm infants developing BPD showed an increased activation of NF- $\mathrm{KB}$ [39]. LPS ( $1 \mu \mathrm{g} / \mathrm{ml}$ for 24 hours) induced the expression of IL-1 $\beta$, IL-6, IL-8 in A549 cells [40]. Under our experimental conditions, no increase of IL-6 after LPS-treatment was observed in the DMBT1- A549 cells and a decrease of IL-6 was found in the DMBT1+ cells. The up-regulation of IL-6 upon PMA stimulation [41] was confirmed in our study in the DMBT1- and DMBT1+ cells, but the effect is much higher in the DMBT1- cells (DMBT1- cells: 160fold, DMBT1+ cells: 20-fold). The same is the case after stimulation with TNFo: The IL-6 increase is 100-fold in control cells and 10-fold in DMBT1 cells. Thus, we consistently observed that DMBT1 suppressed IL-6 in type II lung cells, when challenged with pro-inflammatory stimuli. This is in good agreement with data showing that Dmbt $^{-1-}$ mice were more susceptible to colitis and showed elevated mRNA levels for IL-6 and TNF during inflammation [5]. DMBT1 was up-regulated in intestinal epithelial cells after stimulation with LPS or TNF $\alpha$, but is also able to inhibit LPS-induced NF- $\mathrm{BB}$ activation and cytokine secretion [6]. In intestinal epithelial cells DMBT1 is known to interact with LPS and to antagonize the actions of LPS [42]. Taken together, this may point to antiinflammatory functions of DMBT1 in lung epithelial cells via suppression of IL-6 induction in the presence of proinflammatory stimuli, and that DMBT1 may substitute IL6's functions in up-regulating VEGF. This would be in good agreement with the assumption that DMBT1 may have additional functions at the transition from resolution of inflammation to regeneration in the respiratory tract and other tissues.

\section{Conclusions}

Our data indicate that increased DMBT1 expression induces the production of VEGF and suppresses the IL-6 response in lung epithelial cells, which may point to a function in the transition from inflammation to regeneration.

\section{Abbreviations}

DMBT1: Deleted in malignant brain tumors 1; VEGF: Vascular endothelial growth factor; PMA: Phorbol-12-myristate-13-acetate; RDS: Respiratory distress syndrome; BPD: Bronchopulmonary dysplasia.

\section{Competing interests}

The authors declare that they have no competing interests. 


\section{Authors' contributions}

HM designed research, carried out research, analyzed data, wrote and drafted the manuscript; CN participated in performing the ELISA measurements and the cell culture experiments, CW performed statistical analysis, JM participated in research design and in writing the manuscript, JP assisted in performing research. All authors read and approved the final manuscript.

\section{Acknowledgments}

This work was supported by the Lundbeckfonden Center of Excellence NanoCAN grant, by the DAWN-2020 project financed by Rektorspuljen SDU2020 program, and the MIO project of the OUH Frontlinjepuljen.

\section{Author details}

${ }^{1}$ Department of Pediatrics I, Neonatology, University Hospital Essen, University Duisburg-Essen, Hufelandstr. 55, 45147 Essen, Germany. ${ }^{2}$ Division of Neonatology, Department of Pediatrics, University of Heidelberg, Im Neuenheimer Feld 430, 69120 Heidelberg, Germany. ${ }^{3}$ Institute of Medical Statistics and Biomathematics, University Hospital Mannheim, Ludolf-Krehl-Straße 13-17D, 68167 Mannheim, Germany. ${ }^{4}$ Molecular Oncology and Lundbeckfonden Center of Excellence NanoCAN, Institute for Molecular Medicine, University of Southern Denmark, JB Winsloews Vej 25, 5000 Odense C, Denmark.

\section{Received: 22 November 2014 Accepted: 24 March 2015}

\section{Published online: 08 April 2015}

\section{References}

1. Ligtenberg AJM, Veerman ECI, Nieuw Amerongen AV, Mollenhauer J. Salivary agglutinin/glycoprotein-340/DMBT1: a single molecule with variable composition and with different functions in infection, inflammation and cancer. Biol Chem. 2007;388:1275-89.

2. Madsen J, Mollenhauer J, Holmskov U. Review: Gp-340/DMBT1 in mucosal innate immunity. Innate Immun. 2010:16:160-7.

3. Martínez VG, Moestrup SK, Holmskov U, Mollenhauer J, Lozano F. The conserved scavenger receptor cysteine-rich superfamily in therapy and diagnosis. Pharmacol Rev. 2011;63:967-1000

4. Mollenhauer J, Helmke B, Müller H, Kollender G, Lyer S, Diedrichs L, et al. Sequential changes of the DMBT1 expression and location in normal lung tissue and lung carcinomas. Gene Chromosome Canc. 2002;35:164-9.

5. Renner M, Bergmann G, Krebs I, End C, Lyer S, Hilberg F, et al. DMBT1 confers mucosal protection in vivo and a deletion variant is associated with Crohn's disease. Gastroenterology. 2007;133:1499-509.

6. Rosenstiel P, Sina C, End C, Renner M, Lyer S, Till A, et al. Regulation of DMBT1 via NOD2 and TLR4 in intestinal epithelial cells modulates bacterial recognition and invasion. J Immunol. 2007;178:8203-11.

7. Müller H, Hu J, Popp R, Schmidt MHH, Müller-Decker K, Mollenhauer J, et al. Deleted in malignant brain tumors 1 is present in the vascular extracellular matrix and promotes angiogenesis. Arterioscler Thromb Vasc Biol. 2012;32:442-8.

8. Janér J, Lassus P, Haglund C, Paavonen K, Alitalo K, Andersson S. Pulmonary vascular endothelial growth factor- $C$ in development and lung injury in preterm infants. Am J Respir Crit Care Med. 2006;174:326-30.

9. Voelkel NF, Vandivier RW, Tuder RM. Vascular endothelial growth factor in the lung. Am J Physiol Lung Cell Mol Physiol. 2006;290:L209-21.

10. Maeda S, Suzuki S, Suzuki T, Endo T, Moriya T, Chida M, et al. Analysis of intrapulmonary vessels and epithelial-endothelial interactions in the human developing lung. Lab Invest. 2002;82:293-301.

11. Tuder RM, Petrache I, Elias JA, Voelkel NF, Henson P. Apoptosis and emphysema: the missing link. Am J Respir Cell Mol Biol. 2003;28:551-4.

12. Brown KR, England KM, Goss KL, Snyder JM, Acarregiu MJ. VEGF induces airway epithelial cell proliferation in human fetal lung in vitro. Am J Physiol Lung Cell Mol Physiol. 2001;281:L1001-10.

13. Compernolle V, Brusselmans $K$, Acker $T$, Hoet $P$, Tjwa M, Beck $H$, et al. Loss of HIF-2 $\alpha$ and inhibition of VEGF impair fetal lung maturation, whereas treatment with VEGF prevents fatal respiratory distress in premature mice. Nat Med. 2001;8:702-10.

14. Fehrenbach $H$, Haase M, Kasper M, Koslowski $R$, Schuh D, Muller M. Alterations in the immunohistochemical distribution patterns of vascular endothelial growth factor receptors Flk1 and Flt1 in bleomycin-induced rat lung fibrosis. Virchow Arch. 1999;435:20-31.
15. Perkins GD, Roberts J, McAuley DF, Armstrong L, Millar A, Gao F, et al. Regulation of vascular endothelial growth factor bioactivity in patients with acute lung injury. Thorax. 2005;60:153-8.

16. Akeson AL, Cameron JE, Le Cras TD, Whitsett JA, Greenberg JM. Vascular endothelial growth factor-A induces prenatal neovascularization and alters bronchial development in mice. Pediatr Res. 2005;57:82-8.

17. Meller S, Bhandari V. VEGF levels in humans and animal models with RDS and BPD: Temporal relationships. Exp Lung Res. 2012;38:192-203.

18. Müller H, End C, Weiss C, Renner M, Bhandiwad A, Helmke BM, et al. Respiratory Deleted in Malignant Brain Tumours 1 (DMBT1) levels increase during lung maturation and infection. Clin Exp Immun. 2008;151:123-9.

19. Müller H, End C, Renner M, Helmke BM, Gassler N, Weiss C, et al. Deleted in malignant brain tumors 1 (DMBT1) is present in hyaline membranes and modulates surface tension of surfactant. Respir Res. 2007;8:69.

20. Giedion A, Haefliger H, Dangel P. Acute pulmonary X-ray changes in hyaline membrane disease treated with artificial ventilation and positive endexpiratory pressure (PEP). Pediatr Radiol. 1973;1:145-52.

21. Foster KA, Oster CG, Mayer MM, Avery ML, Audus KL. Characterization of the A549 cell lines as a type II pulmonary epithelial cell model for drug metabolism. Exp Cell Res. 1998;243:359-66.

22. End C, Lyer S, Renner M, Stahl C, Ditzer J, Holloschi A, et al. Generation of a vector system facilitating cloning of DMBT1 variants and recombinant expression of functional full-length DMBT1. Protein Expr Purif. 2005:41:275-86.

23. Gurkan OU, He C, Zielinski R, Rabb H, King LS, Dodd-o JM, et al. Interleukin-6 mediates pulmonary vascular permeability in a two-hit model of ventilatorassociated lung injury. Exp Lung Res. 2011;37:575-84.

24. End C, Bikker F, Renner M, Bergmann G, Lyer S, Blaich S, et al. DMBT functions as pattern-recognition molecule for poly-sulfated and polyphosphorylated ligands. Eur J Immunol. 2009;39:833-42.

25. Mura M, Dos Santos CC, Stewart D, Liu M. Vascular endothelial growth factor and related molecules in acute lung injury. J Appl Physiol. 2004:97:1605-17.

26. Lassus P, Ristimäki A, Ylikorkala O, Viinikka L, Andersson S. Vascular endothelial growth factor in human preterm lung. Am J Respir Crit Care Med. 1999;159:1429-33.

27. Bhatt AJ, Pryhuber GS, Huyck H, Watkins RH, Metlay LA, Maniscalco WM. Disrupted pulmonary vasculature and decreased vascular endothelial growth factor, Flt-1, and TIE-2 in human infants dying with bronchopulmonary dysplasia. Am J Respir Crit Care Med. 2001;164:1971-80.

28. Ambalavanan N, Novak ZE. Peptide growth factors in tracheal aspirates of mechanically ventilated preterm neonates. Pediatr Res. 2003;53:240-4.

29. Koyama S, Sato E, Tsukadaira A, Haniuda M, Numanami H, Kurai M, et al. Vascular endothelial growth factor mRNA and protein expression in airway epithelial cell lines in vitro. Eur Respir J. 2002;20:1449-56.

30. Boussat S, Eddahibi S, Coste A, Fataccioli V, Gauge M, Housset B, et al. Expression and regulation of vascular endothelial growth factor in human pulmonary epithelial cells. Am J Physiol Lung Cell Mol Physiol. 2000;279:L371-8.

31. Shenberger JS, Zhang L, Powell RJ, Barchowsky A. Hyperoxia enhances VEGF release from $A 549$ cells via post-transcriptional processes. Free Radic Biol Med. 2007:43:844-52

32. Buchanan FG, Chang W, Sheng H, Shao J, Morrow JD, DuBois RN. Upregulation of the enzymes involved in prostacyclin synthesis via Ras induces vascular endothelial growth factor. Gastroenterology. 2004;127:1391-400.

33. Schuette R, LaPointe MC. Phorbol ester stimulates cyclooxygenase-2 expression and prostanoid production in cardiac myocytes. Am J Physiol Heart Circ Physiol. 2000:279:H719-25.

34. Xu H, Czerwinski P, Hortmann M, Sohn H-Y, Förstermann U, Li H. Protein kinase $\mathrm{C}$ a promotes angiogenic activity of human endothelial cells via induction of vascular endothelial growth factor. Cardiovasc Res. 2008;78:349-55.

35. Luo H, Chen Z, Jin H, Zhuang M, Wang T, Su C, et al. Cyclooxygenase-2 upregulates vascular endothelial growth factor via a protein kinase $C$ pathway in non-small cell lung cancer. J Exp Clin Cancer Res. 2011;30:6.

36. Thaikoottathil JV, Martin RJ, Zdunek J, Weinberger A, Rino JG, Chu HW. Cigarette smoke extract reduces VEGF in primary human airway epithelial cells. Eur Respir J. 2009;33:835-43.

37. Cayabyab RG, Kwong K, Jones C, Minoo P, Durand M. Lung inflammation and pulmonary function in infants with meconium aspiration syndrome. Pediatr Pulmonol. 2007:42:898-905.

38. Thompson A, Bhandari V. Pulmonary biomarkers of bronchopulmonary dysplasia. Biomarker Insights. 2008;3:361-73. 
39. Aghai ZH, Kode A, Saslow JG, Nakhla T, Farhath S, Stahl GE, et al. Azithromycin suppresses activation of nuclear factor-kappa B and synthesis of pro-inflammatory cytokines in tracheal aspirate cells from premature infants. Pediatr Res. 2007:62:483-8.

40. Donnarumma G, Paoletti I, Buommino E, lovene MR, Tudisco L, Cozza V, et al. Anti-inflammatory effects of moxifloxacin and human $\beta$-defensin 2 association in human lung epithelial cell line (A549) stimulated with lipopolysaccharide. Peptides. 2007;28:2286-92.

41. Kang W, Nielsen O, Fenger C, Madsen J, Hansen S, Tornoe I, et al. The scavenger receptor, cysteine-rich domain-containing molecule gp-340 is differentially regulated in epithelial cell lines by phorbol ester. Clin Exp Immunol. 2002;130:449-58.

42. Kang SS, Jeon JH, Woo SJ, Yang JS, Kim KW, Yun CH, et al. IFNhuman intestinal epithelial cells responsive to lipopolysaccharide of Vibrio cholerae by down-regulation of DMBT1. Comp Immunol Microbiol Infect Dis. 2012;35:345-54.

\section{Submit your next manuscript to BioMed Central and take full advantage of:}

- Convenient online submission

- Thorough peer review

- No space constraints or color figure charges

- Immediate publication on acceptance

- Inclusion in PubMed, CAS, Scopus and Google Scholar

- Research which is freely available for redistribution 